ARTIGO

\title{
A autoridade docente e a sociedade da informação: o papel das tecnologias informacionais na docência
}

\author{
Leonardo Humberto Soares a \\ Carlos Ângelo de Meneses Sousa ${ }^{b}$ \\ Ricardo Spindola Mariz ${ }^{c}$ \\ Jaci Maria Ferraz de Menezes ${ }^{d}$
}

\section{Resumo}

Objetivou-se identificar de que maneira as tecnologias e a prática docente, frente à "Sociedade da Informação", reforçam, ou põem em xeque, a percepção do professor sobre a sua autoridade. A reflexão sobre o conceito de autoridade de Hannah Arendt direcionou o pilar teórico e conceitual do estudo. Como resultado, identificou-se que o aluno possui facilidade em interagir com a tecnologia, mas essa facilidade não ultrapassa o seu uso no contexto comunicacional e de lazer; que $\mathrm{o}$ acesso dos alunos às novas bases informacionais pode gerar um sentimento de perda da autoridade por parte do professor despreparado; e que não é o domínio da tecnologia pelo professor que estabelece a sua autoridade, mas sim, a constituição de significado que é construído durante a relação educativa.

Palavras-chave: Autoridade docente. Crise. Tecnologia. Informação. Incerteza.

\section{Introdução}

$\mathrm{O}$ artigo objetiva identificar de que maneira as novas Tecnologias Informacionais e Comunicacionais (TICs), considerando o volume informacional produzido, e a prática docente, frente à "Sociedade da Informação", reforçam e/ou desconstroem a percepção do professor de Ensino Superior sobre a sua autoridade em sala

\footnotetext{
a Centro Universitário de Brasília/União Marista do Brasil, Brasília, DF, Brasil.

b Universidade Católica de Brasília, Brasília, DF, Brasil.

c União Marista do Brasil, Brasília, DF, Brasil.

d Universidade do Estado da Bahia, Salvador, BA, Brasil.
} 
de aula. A pesquisa partiu da indagação de que o sentimento de "crise da autoridade", que é verbalizado por parte dos docentes, pode estar vinculado às novas dinâmicas sociais emergentes do desenvolvimento tecnológico e informacional visto nos últimos 40 anos, e que se apresenta cada vez mais inserido no contexto social.

A pesquisa revelou aspectos que podem contribuir na compreensão do próprio ato educativo e dos fenômenos que fazem parte da rotina do professor. $\mathrm{O}$ trabalho se fundamentou nas reflexões apresentadas por Bauman (2011) e Castells (2009) para compreender como a contemporaneidade está reagindo aos eventos de mudança no que vem sendo chamado de sociedade da informação. Sobre esse cenário, pintou-se o enredo da discussão desse estudo e teve Arendt (2011) como fio condutor para o conceito de crise da autoridade docente.

A fenomenologia foi utilizada enquanto método científico condutor para os procedimentos aplicados. A pesquisa se caracterizou como exploratória quanto ao fim e pesquisa de campo, e empírica quanto aos meios. A partir da abordagem qualitativa, foi utilizada a entrevista semiestruturada e a observação assistemática como técnicas para a geração de dados. O Discurso do Sujeito Coletivo (DSC), conjuntamente com a análise interparticipante foram utilizados como instrumentais para a sua contextualização. Partindo do princípio de que o domínio da informação e do conhecimento no Ensino Superior estabelece relações um pouco mais tangíveis de empoderamento do professor, foi definido que esse espaço seria a fonte para a geração dos dados da pesquisa, sendo focados, especificamente, os professores oriundos das graduações em licenciatura e que exerciam a docência em uma Instituição de Ensino Superior privada localizada no Distrito Federal.

Para a seleção da Instituição participante, foram usados os seguintes critérios: estar situada no Distrito Federal; não possuir restrições relacionadas à infraestrutura, ter formação de professores, salário ou apoio pedagógico; possuir alunos de nível socioeconômico com acesso ao consumo de tecnologias; ter sido avaliada pelos instrumentos externos de qualidade do Ministério da Educação e Cultura.

Já os professores participantes foram selecionados a partir dos seguintes critérios: terem formação adequada para a sua disciplina de origem; possuírem avaliação interna sobre o uso de recursos tecnológicos em sala de aula e docentes com titulação mínima de mestrado dentro da sua área de atuação. Não foram definidas questões de gênero para seleção e a média geral de experiência 
profissional dos participantes foi de quase 15 anos na docência. A avaliação prévia sobre a pré-disposição do professor quanto ao uso das tecnologias (pela própria Instituição) permitiu a constituição de dois grupos experimentais, com a mesma quantidade de participantes, denominados de "resistentes" e "potencializadores", os quais oportunizaram o contraste de duas posições diferentes quanto às tecnologias.

\section{Perspectivas sobre a nova geração de alunos}

Se as tecnologias permeiam a Educação, a escola atual é tida como retrógrada e pouco eficiente em responder as demandas tecnológicas contemporâneas (FRANKY; CHIAPPE, 2018). Pressionada por uma sociedade tecnológica e informacional, as instituições educacionais investem recursos volumosos para aquisição de infraestruturas tecnológicas com o objetivo de aumentar a qualidade de sua formação. Contudo, os resultados alcançados não parecem justificar esse investimento (BLÖMEKE; BUCHHOLTZ, 2017; CHRISTENSEN; HORN; JOHNSON, 2012), tendo em vista que não foram sustentáveis ao longo do tempo (SOSA; MAZUOLLI, 2019).

Muitos autores defendem que essa nova geração de alunos possui uma série de competências tecnológicas, que exige mudanças na estrutura e na metodologia das instituições educacionais (PRENSKY, 2004; TAPSCOT, 2008). Por outro lado, alguns autores também apontam que muitos dos professores que acolhem esses alunos não possuem a formação tecnológica adequada para recebê-los, mantendo uma prática tradicional que não atende mais às expectativas da contemporaneidade (CECCHETTINI, 2011; PRENSKY, 2004). A partir desse contexto, potencializa-se um entendimento de que a nova geração de alunos está mais adaptada ao uso da tecnologia do que a geração que lhe precedeu, enquanto os seus professores são resistentes ao uso das tecnologias e sentem-se ameaçados por suas possibilidades. Contudo, o que se verificou nessa pesquisa é que esse argumento pode estar equivocado, e que novas reflexões devem ser feitas, a partir da compreensão da prática docente.

Se para o aluno, a Educação e o professor não fazem mais sentido, para o professor, o aluno é desleixado, desrespeitoso e pouco envolvido no processo de ensino-aprendizagem. Como consequência, fortalece-se o entendimento de que existe um cenário de crise da Educação e de perda da autoridade do professor. Esse entendimento pode ser percebido na fala de estudantes e professores lotados no Ensino Superior, em vários tipos de graduação (ANASTASIOU, 2006; LIMA; GILLO, 2008; SOUSA, 2012; LIMA; FONTE-BOA, 2015). 
Esse contexto gerou uma teoria geracional que categoriza os indivíduos por meio da influência que os fatores históricos tiveram sobre sua percepção da realidade (TAPSCOTT, 2008). Assim, surgem definições como geração "Tradicional", "Baby-boomers", "Geração X", "Geração Y" e "Geração Z". Verifica-se que essa teoria geracional encontra vários pesquisadores simpatizantes, como Cecchettini (2011), Jukes e Dosaj (2004), Oliveira (2009) e Prensky (2004).

Outros autores apresentam uma visão diferenciada dessa teoria geracional. Enguita (2016), por exemplo, afirma que a sociedade contemporânea pode ser identificada como uma sociedade de mudança. Não se trata de uma mudança trivial e comum, tal qual se tem acompanhado na história, mas de transformações sociais muito velozes e nunca vistas em outros momentos. Já Howe e Strauss (2009) discutem como essas novas gerações colocam-se em uma posição positiva de mudanças de hábitos e de costumes, ao mesmo tempo em que partem de uma expectativa verdadeira de fazer a diferença no mundo em que vivem.

Contudo, há estudos contrários a essa posição e que apontam sobre uma apatia dessa nova geração. Bauman (2011), por exemplo, apresenta uma visão crítica sobre essas novas juventudes. Bauerlein (2008) argumenta como os jovens da contemporaneidade são desinteressados da realidade do mundo. O psicólogo Hallowell (2007) defende que os aparelhos eletrônicos podem provocar distúrbios como déficit de atenção ou distrações mais simples, gerando indivíduos superficiais e com pouco poder de concentração.

\section{A crise da educação e a autoridade docente}

$\mathrm{O}$ argumento da Crise da Educação ocorre em paralelo à questão Tecnológica. Esse discurso apoia-se na queixa sobre o baixo salário dos professores, a falta de perspectiva da carreira, a desconstrução da infraestrutura na escola e, principalmente, sobre o desinteresse e indisciplina dos alunos.

Historicamente, a Educação sempre passou por momentos capitais, em que ficava evidente que os "pressupostos e as estratégias experimentadas e em aparência confiáveis estavam perdendo contato com a realidade e precisavam ser revistas ou reformadas" (BAUMAN, 2011, p. 112). Arendt (2011) também já apontava que os aspectos socioeconômicos e políticos não esgotam o contexto de crise na Educação. Para a autora, também deveria levar-se em consideração os aspectos centrais da modernidade e como as novas forças existentes passaram a lidar com o passado e com a tradição herdada. 
Assim, a novidade (ou surpresa) não seria a crise em si que se manifesta também na Educação, mas, as novas faces que essa crise demonstra. Nesse contexto, chama a atenção o papel que o professor assume nesse cenário de crise, principalmente, em sua dimensão de autoridade e legitimidade. Ao se afirmar que a crise da Educação faz parte de um contexto maior (a crise da tradição e do passado), percebe-se que o professor, que tem a tarefa de mediar as relações entre o conhecimento antigo e o conhecimento novo, fica fragilizado em seu papel, visto que a sua profissão exige um grande respeito justamente pela tradição e pelo passado, sendo esses os alvos maiores da crise da modernidade. Landweer e Newmark (2017) destacam que a modernidade trouxe mudanças na percepção da autoridade que, se outrora era nítida e visível, hodiernamente assume novas configurações, menos dependentes de imagens masculinas tradicionais, e de formas pouco visíveis.

Sobre esse tema, Furlani (2012) comenta que a autoridade docente é vista na relação cultural que estabelece a institucionalização do poder do professor como a autoridade maior em sala de aula, sendo ele responsável pela condução dos alunos em seu desempenho acadêmico e desenvolvimento social. Assim, a instituição "escola" assume o professor como o agente de autoridade formalmente instituído para o ato de ensinar. Contudo, a autoridade, em seu caráter mais autoritário, também pode ser identificada na história da Educação, principalmente em instituições disciplinares com caráter religioso ou militar. Para Durkheim (2008), o respeito à regra pressupõe o respeito pelo professor e é nessa base que se sustenta a autoridade docente. Segundo o autor, a vida é dura e cheia de perigos, e seria incoerente criar um ambiente escolar onde tudo fossem risos, brincadeiras e divertimento. O papel da escola é preparar para a vida e existe um contexto de certo sacrifício em seu desenvolvimento.

Em paralelo a esse fenômeno, surge o debate sobre a "Sociedade da Informação" e as suas transformações sociais, materializadas em vários movimentos políticos, mercadológicos e culturais. Arendt (2011, p. 239) já afirmava que a competência maior do professor consistia "em conhecer o mundo e em ser capaz de transmitir esse conhecimento aos outros". Nesse caso, a sua autoridade "funda-se no seu papel de responsável pelo mundo". Contudo, as velocidades das mudanças vistas na contemporaneidade parecem criar um descompasso entre o ser (professor) e o conhecer (o mundo).

\section{Hannah Arendt: crise e autoridade}

Para Arendt (2011), o que se percebe na Educação faz parte de uma crise bem mais ampla e que engloba a autoridade, a tradição, a política, o espaço público 
e a responsabilidade individual. Essa crise maior seria intrínseca à crise da modernidade, que repercutiria em um contexto bem mais complexo.

Contudo, antes de ser um problema, Arendt (2011) percebe, na crise, a possibilidade de discutir as lacunas e os espaços de conflito na Educação. A crise surge como um momento para se buscar respostas, novas ou antigas, para o fenômeno que a autora percebe como sendo a essência da Educação: a natalidade, ou seja, o fato de novos seres humanos nascerem e precisarem trilhar um caminho para conhecerem e desenvolverem-se nesse mundo que os espera.

Nesse caso, a Educação mostra-se conservadora em sua função maior, que é garantir, não somente a continuidade do novo indivíduo que chega a esse mundo, mas, também, garantir que esse mundo, que já existia, sobreviva a esse novo indivíduo. A continuidade do mundo estaria vinculada ao equilíbrio existente em manter-se o conhecimento do passado para que seja possível transformar o futuro, e não em se desconstruir o que é tradição em função da mudança pela mudança.

Arendt (2011) defende que uma "sociedade de massas", que fomenta a perda da autoridade e da tradição, a exacerbação do consumo, a priorização do trabalho em detrimento do convívio social, a homogeneização em detrimento da diversidade, a desconstrução do passado, o menosprezo à hierarquia e o culto à novidade fortalecem a ideia de crise. Esses fenômenos acabam por potencializar um encurtamento das fronteiras existentes entre adultos e crianças, demonstrando a incapacidade dos adultos em introduzir os novos indivíduos que estão chegando à um mundo que eles mesmos não entendem.

Assim, a tarefa de mediar o ingresso dessa criança no mundo dos adultos acaba ficando, muitas vezes, a cargo unicamente da escola. Para tanto, a Educação se pauta em uma de suas premissas mais importantes: a autoridade do professor.

Segundo a autora, ao se refletir sobre o conceito de autoridade do professor, deve-se desassociá-lo do conceito de competência do professor. Enquanto a competência envolve a sua capacidade de conhecer o mundo e ser capaz de transmitir esse conhecimento ao outro, a autoridade constitui-se no processo de aceitação do papel de responsável por esse mundo e na condução desse novo indivíduo no percurso para a sua compreensão. Em sua autoridade, o professor possui a legitimidade de apresentar à criança a seguinte mensagem: "Eis aqui o nosso mundo!" (ARENDT, 2011, p. 239).

Se a crise anunciada da Educação se inicia como consequência de uma "sociedade de massa", ela se fortalece com a desconstrução da autoridade do professor. Essa 
desconstrução dá-se por meio de um abandono da tradição e com o banimento do sentido de passado. Cria-se, para o educador, um antagonismo estrutural, que coloca em xeque a sua função, visto que é seu papel manter o equilíbrio entre o antigo e o novo.

\section{Apresentação e análise dos dados}

O uso da técnica do DSC teve como objetivo analisar o material oral gerado nas entrevistas semiestruturadas, a partir das ideias centrais e expressões-chave e suas recorrências, que compõem um ou vários discursos-síntese. O DSC produzido se caracteriza como sendo um discurso-síntese homogêneo e redigido na primeira pessoa do singular (LEFEVRE; LEFEVRE, 2005). Nele, a percepção de cada participante passou a constituir uma declaração expressa em forma de um discurso coletivo (construído artificialmente), permitindo a sua mensuração a partir da incidência dos pensamentos individuais e de categorias a posteriori. A observação assistemática levou em consideração as reações visuais e gesticulavas dos participantes durante a entrevista e os momentos de contatos diretos realizados com a Instituição. As observações coletadas foram anotadas no ato de execução da entrevista/contato.

Foram realizadas oito entrevistas de profundidade que totalizaram cerca de 340 minutos de gravação com os professores participantes, sendo uma parte "resistente" ao uso das tecnologias e outra "potencializadora" do seu uso em sala de aula. Essas entrevistas foram desgravadas com o software Express Scribe e analisadas por meio do software Qualiquantisoft, pertencente à Universidade de São Paulo (USP).

A análise realizada pelo DSC identificou 76 expressões-chave que foram categorizadas em 23 ideias centrais reincidentes. O movimento de análise focou a relação das forças existentes entre essas categorias e deu pistas para as dinâmicas sociais que estão envolvidas no contexto estudado. $O$ conceito de "Força" utilizado refere-se ao nível de reincidência/vigor de ideias centrais e expressões-chave encontradas nas categorias e transformadas em percentual. O Quadro 1 apresenta essas convergências.

Quadro 1 - Força das categorias

\begin{tabular}{|l|c|c|}
\hline Categoria & Código & Força \\
\hline Incerteza quanto à escolha da profissão & $\mathrm{C} 01$ & $7 \%$ \\
\hline Docência como escolha para carreira & $\mathrm{C} 02$ & $4 \%$ \\
\hline Graduação com foco para pesquisa & $\mathrm{C} 03$ & $5 \%$ \\
\hline Escolha em continuar na carreira docente & $\mathrm{C} 04$ & $5 \%$ \\
\hline
\end{tabular}

Continua 
Continuação

\begin{tabular}{|l|c|c|}
\hline Docência como trabalho provisório & $\mathrm{C} 05$ & $3 \%$ \\
\hline Crise estrutural & $\mathrm{C} 06$ & $7 \%$ \\
\hline Mudanças ocasionadas pela tecnologia & $\mathrm{C} 07$ & $3 \%$ \\
\hline Percepção de melhora na educação & $\mathrm{C} 08$ & $3 \%$ \\
\hline Leitura deficiente & $\mathrm{C} 09$ & $3 \%$ \\
\hline Participação - equipamentos eletrônicos & $\mathrm{C} 10$ & $3 \%$ \\
\hline Desinteresse pela aula & $\mathrm{C} 11$ & $3 \%$ \\
\hline Mercantilização do ensino & $\mathrm{C} 12$ & $3 \%$ \\
\hline Pouca idade dos alunos & $\mathrm{C} 13$ & $3 \%$ \\
\hline Aluno aprecia expressar as suas opiniões & $\mathrm{C} 14$ & $5 \%$ \\
\hline Consumismo exacerbado & $\mathrm{C} 15$ & $3 \%$ \\
\hline Domínio tecnológico na dimensão comunicacional e de entretenimento & $\mathrm{C} 16$ & $8 \%$ \\
\hline Incapacidade de lidar com o grande volume informacional & $\mathrm{C} 17$ & $11 \%$ \\
\hline Perda da autoridade & $\mathrm{C} 18$ & $3 \%$ \\
\hline Relações mais difíceis em função da tecnologia & $\mathrm{C} 19$ & $3 \%$ \\
\hline Espaço para construção conjunta & $\mathrm{C} 20$ & $8 \%$ \\
\hline Simplificação da realidade por parte do aluno & $\mathrm{C} 21$ & $3 \%$ \\
\hline O uso de tecnologia pelos alunos pode atrapalhar a aula & $\mathrm{C} 22$ & $5 \%$ \\
\hline A autoridade não está vinculada à tecnologia & $\mathrm{C} 23$ & $4 \%$ \\
\hline
\end{tabular}

Fonte: Elaborado pelos autores (2016) com dados da pesquisa de campo

O Gráfico 1 radar apresenta as categorias encontradas na análise do DSC.

Gráfico 1 - Força das categorias convergentes<smiles>CCCCC(C)(C)C(=O)O</smiles>

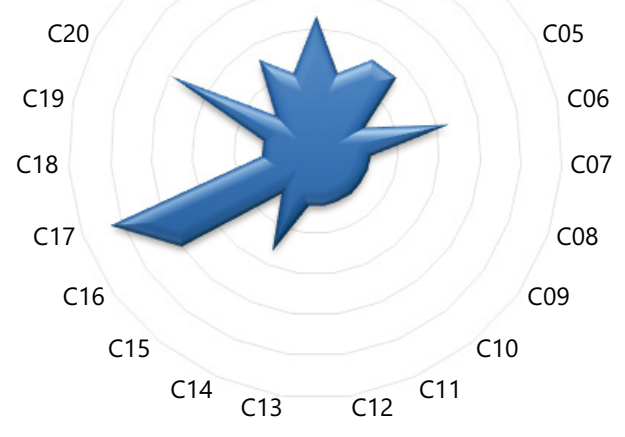

Fonte: Elaborado pelos autores (2016) com dados da pesquisa de campo 
O que se pode perceber é que a crise de autoridade não é fomentada, necessariamente, pelas tecnologias informacionais e comunicacionais, ainda que esses aspectos sejam relevantes para o seu entendimento. Nesse sentido, a constituição da crise de autoridade se aproxima, consideravelmente, do contexto apresentado por Arendt (2011) e que aponta como uma das suas principais causas a dificuldade existente por parte do professor em conseguir encaminhar o seu aluno para o conhecimento de um mundo que se transforma de maneira cada vez mais rápida. Ainda que as hipóteses que foram identificadas demonstrem essa perspectiva, compreende-se que a principal contribuição desse artigo talvez esteja na identificação de três importantes fenômenos que parecem ser essenciais no debate em curso.

No primeiro fenômeno, é abordado o domínio tecnológico e a capacidade de assimilação informacional que é desenvolvida pelo aluno e que foi identificada na seguinte hipótese: o aluno possui facilidade em interagir com a tecnologia, mas essa facilidade não ultrapassa o seu uso no contexto comunicacional e de entretenimento. Ter uma facilidade maior no uso da tecnologia não parece estar garantindo práticas mais efetivas na resolução de problemas do cotidiano ou na aquisição de novos conhecimentos. Essa hipótese foi constituída tendo como base as categorias C16 (Domínio tecnológico na dimensão comunicacional e de entretenimento) e $\mathrm{C} 17$ (Incapacidade de lidar com o grande volume informacional) que se apresentaram como as mais recorrentes em todo o estudo, conforme apontado no Quadro 1.

Uma primeira reflexão recai sobre a produção acadêmica que defende a ideia de que a nova geração de alunos já é possuidora de um domínio tecnológico e informacional intrínseco e um desenvolvimento diferenciado em seu processo de formação e produção de conhecimento. Essa perspectiva pode ser vista na defesa da teoria geracional de Tapscott (2008), que aponta os indivíduos dessa geração como profundos consumidores de tecnologia.

Prensky (2004), Schlemmer (2006) e Takahashi (2000) também possuem uma percepção próxima a esse contexto ao entender que essa geração conseguiria absorver uma grande quantidade de informação, e utilizá-la para tomar decisões mais rápidas do que a geração anterior. São muitos os que defendem as possíveis competências de uma geração que teria nascido sob a égide tecnológica e informacional.

Uma outra leitura possível sobre esse cenário é que, apesar de todas as competências positivas que esses nativos digitais trazem para a sala de aula, a 
qualidade do processo formativo e a construção do conhecimento necessário para a sua inclusão no mundo adulto ainda estão abaixo do esperado. Nesse caso, se o problema não se encontra no aluno, poderia estar no professor, que não domina ou não é participante da mesma dimensão informacional e tecnológica do aluno. É esse tipo de racionalização rasa que permite apontamentos como visto em Cecchettini (2011) e que tendem a culpar o professor pelos problemas educacionais existentes, a partir de um discurso sobre o seu pouco trânsito nesse universo digital.

Contradizendo essas interpretações, ainda que seja em caráter restrito a seus participantes, o resultado obtido pela pesquisa apontou que os professores entrevistados não conseguiam identificar em seus alunos essas competências que são defendidas pela literatura. $\mathrm{O}$ uso da tecnologia pelos alunos não garante as competências necessárias para transformar o grande volume informacional existente em um conhecimento que transforme a sua vida ou que permita o reconhecimento do mundo a que ele está dirigindo-se.

Nesse sentido, nasce uma segunda leitura possível a partir da problematização que Arendt (2011) levanta. A autora compreendia que a Educação, por meio da atuação do professor, caberia a delicada tarefa de incluir os novos indivíduos em um mundo que já existia antes, que lhes seria estranho e pouco compreensível, mas que deveria persistir após a sua morte. Nesse caso, o professor seria aquele que, de posse do conhecimento desse mundo, apontaria aos seus alunos os caminhos para a sua compreensão. Contudo, devido ao advento de uma sociedade de massa que potencializa uma perda da autoridade e da tradição, que foca no consumo exacerbado, que menospreza a hierarquia e fortalece o culto à novidade, esse professor estaria perdendo a sua capacidade de introduzir esses novos indivíduos chegantes em um mundo que muda rapidamente e onde, por vezes, o próprio professor não entende.

Somando-se a esse contexto, poder-se-ia argumentar que as tecnologias afastariam ainda mais o professor desse papel, pois permitiriam ao aluno reconhecer, em outras fontes, esse próprio mundo que o professor deveria demonstrar. Se aceito, esse argumento iria reforçar a tese de que as TICs aumentariam a crise de autoridade pela qual passa o professor, tendo em vista que ela diminuiria a sua legitimidade como "aquele que conhece o mundo" perante seus alunos.

Entretanto, o que se pode inferir a partir dos resultados encontrados é que, apesar de o aluno aderir facilmente ao uso da tecnologia e ter acesso a um grande volume informacional, ele continua a ter dificuldades em perceber esse mesmo mundo 
em que vive. Ou seja, o acesso a outras fontes de informação (excluindo-se o professor) não garante ao aluno o reconhecimento desse mundo, sendo-lhe ainda estranho e temeroso, pois a informação, por si só, não estabelece as relações de sentido e de significado que são importantes para a sua inclusão.

Reforça-se, então, o entendimento de que a tecnologia e a informação fazem parte da rotina do aluno. Contudo, ele ainda depende do papel do professor para dar sentido e significado, tanto na utilização dessa tecnologia, quanto na gestão do grande volume informacional que ela proporciona.

Apesar de essa inferência parecer plausível dentro do contexto da pesquisa, percebeu-se que ainda há lacunas por parte do professor no que se refere ao entendimento sobre o novo papel docente demandado. Essa lacuna poderia ser expressa, no que foi reconhecido como o segundo fenômeno identificado: $o$ acesso dos alunos às novas bases informacionais pode gerar um sentimento de perda da autoridade naquele professor que não está preparado para lidar com essa realidade, não pela informação em si, mas pela incapacidade de lidar com o fato de não ser mais a fonte inquestionável de conhecimento na sala de aula.

Essa dinâmica foi constituída tendo como base a categoria C14 (Aluno aprecia expressar as suas opiniões) que, além da frequência estabelecida, foi também identificada no momento das entrevistas por meio da observação assistemática. Em relação a isso, percebeu-se que alguns professores possuíam maior resistência a um posicionamento mais opinativo ou questionador do discente. Em vez de perceber tal posicionamento como uma oportunidade para manter o interesse do aluno sobre o tema e ampliar o escopo da sua aula, esses professores, geralmente, percebiam a questão como uma afronta à sua posição de autoridade. Tendo em vista esse resultado, pode-se inferir que ainda há resistência por parte do professor em abrir mão do que seria a sua principal competência: o domínio sobre uma determinada área do saber.

Essa resistência poderia ser relacionada ao que Bauman (2011) assinala como uma das mais incisivas críticas aos alicerces da Educação: a solidez das coisas. Mais especificamente, a solidez dos conhecimentos, dos valores e das relações humanas por ela apresentados. Essa solidez pode ser vista na forma e nos procedimentos que ainda são utilizados na condução do ato educativo. A configuração da sala de aula em formato de colunas e linhas, as matrizes curriculares, o papel institucionalizado do docente enquanto autoridade, a priori, e a própria formação do professor poderiam expressar essa solidez na Educação. 
Partindo-se da premissa de que os objetos e os valores da contemporaneidade possuem pouca capacidade de permanência e imutabilidade em períodos longos de tempo, a insistência do professor em pautar-se unicamente nos saberes (enquanto conteúdos informacionais) que construiu ao longo da sua carreira profissional, acabam por fragilizar o seu papel de autoridade em sala de aula em decorrência da sua incapacidade de acompanhar o ritmo e a dimensão da produção de informações e de conteúdos que hoje é viabilizada pelas tecnologias informacionais.

Quando o professor estabelece essa "condição" de ser o principal ou o único repositório de saberes em sala de aula, além de ser uma condição de deslealdade, haja vista suas limitações físicas, acaba por colocá-lo em situações constrangedoras tendo em vista a potencialidade latente que cada um dos seus alunos possui em apresentar conteúdos que ele desconhece, ou não domina, por meio dos seus recursos tecnológicos.

Ainda, verifica-se a resistência por parte do professor em compreender que o processo de Educação contemporâneo ocorre, por vezes, muito mais intensamente fora da escola do que entre os seus muros. Obviamente, esse cenário pode gerar inquietações naquele professor que entender esse movimento como um ataque à sua continuidade enquanto profissional da Educação. Por outro lado, o professor que esteja flexível para as mudanças que ocorrem no contexto do que Bauman (2011) denomina de "modernidade líquida", pode aproveitar as possibilidades tecnológicas existentes para ampliar o seu instrumental docente, principalmente quando esse professor deixa de ser simplesmente um consumidor de informação e passa a ser um produtor de conhecimentos em sua sala de aula.

Nesse sentido, Castells (2009) já apontava que a informação passou a constituir-se como matéria-prima para a geração de valor na contemporaneidade, de forma a permitir que o indivíduo atue diretamente sobre ela e materialize produtos e soluções nas mais diversas áreas, inclusive na Educação. O professor, que pode ser visto com naturalidade dentro de uma perspectiva de "trabalhador do conhecimento", já estaria atuando em uma dimensão profissional que manipula o que seria o objeto de maior valia no "mercado" atual: o conhecimento.

Entretanto, é importante desconstruir a expectativa de uso que a sociedade construiu a respeito da meta final a ser alcançada pela Educação. Segundo Bauman (2011), a jornada do conhecimento humano pelo mundo moderno se constituiu em duas frentes: a tentativa de representar-se (e conhecer) o mundo em sua totalidade; 
e a intenção de criarem-se modelos desse mundo que pudessem ser aplicados no processo de formação desse indivíduo. Nesse contexto, o uso da tecnologia assumiria uma posição de destaque enquanto instrumental, que permitiria que esses objetivos fossem atingidos.

Contudo, à medida que o mundo se tornou mais inteligível e a quantidade de informações foi crescendo de maneira exponencial, também aumentou a distância no reconhecimento de sua totalidade, pois cada nova informação trouxe uma infinidade de lacunas e de questionamentos que tornaram ainda mais complexa a sua compreensão. A imensa quantidade de informações construídas nesse processo, em vez de contribuir para o desenvolvimento das estratégias educacionais, criou um cenário tamanho de caos e desordem que, mesmo com todos os recursos possíveis de organização informacional, ainda não se consegue viabilizar a exploração da enorme massa de informações existentes pelas instituições de ensino, até mesmo pelos indivíduos que dela fazem uso.

É a partir desse contexto que Bauman (2011) defende a mudança do papel do professor tradicional e autoritário para a figura de professor-orientador, que consegue mostrar caminhos alternativos e diferentes para o processo de ensino-aprendizagem, em vez de apenas "comunicar" os conhecimentos necessários para a formação do aluno. $\mathrm{O}$ autor espera que esse professor-orientador ajude os alunos a evidenciar as suas aspirações e competências e apresente um conhecimento prático do tipo "como fazer", e não somente um conhecimento do tipo "saber que existe". Nessa mesma linha de pensamento, identificou-se o terceiro fenômeno dessa pesquisa: a emergência de uma nova estratégia vista nas relações entre professores e alunos e que se pauta na compreensão do outro como parte diretamente envolvida no ato educativo parece acomodar, de maneira mais harmoniosa, as relações de autoridade na sala de aula.

Essa dinâmica foi constituída tendo como base a categoria C20 (Espaço para construção conjunta) e que aparece como terceira categoria mais reincidente no processo de análise do DSC, logo após as categorias C16 (Domínio tecnológico na dimensão comunicacional e de entretenimento) e C17 (Incapacidade de lidar com o grande volume informacional), conforme apontado no Quadro 1.

A esse respeito, os professores que expressaram o entendimento de que espaços construídos conjuntamente tendem a ser mais harmoniosos, produtivos e acolhedores, também confirmaram perceber uma relação mais respeitosa com os seus alunos e a constituição de uma autoridade pautada na legitimação por parte de suas turmas. Também foi possível perceber, tanto nas entrevistas 
quanto na observação assistemática, que os professores que atuavam dessa forma apresentavam uma percepção bem mais flexível sobre o papel docente e sobre os seus procedimentos na relação educativa. Nesses casos, os professores comentaram sobre as suas limitações intelectuais e verbalizaram a constatação de não serem os "donos" do saber e de aprenderem continuamente com os seus alunos.

A ocorrência dessas situações relatadas acaba por reforçar o conceito apresentado por Postic (1990), que defende que as relações existentes entre professores e alunos tendem a ser afetivas e cognitivas, possuindo um desenvolvimento e uma história que são construídos ao longo do processo educativo. Ao se corroborar esse argumento, fortalece a intuição de que os meios e as condições aplicadas na prática docente impactam diretamente nas relações sociais constituídas entre o professor e o aluno, o que modificaria, também, a percepção sobre a autoridade construída a partir dessa relação.

Talvez essa seja a competência essencial para que o professor alcance o que Arendt (2011) denomina de "conhecimento do mundo". Somente ao reconhecer que o mundo é fluido e incerto e que as suas capacidades são limitadas frente a essa dinâmica, é que o professor conseguiria construir o seu instrumental de reconhecimento desse mesmo mundo. Ao colocar-se em uma posição de respeito bidirecional com o seu aluno, o professor pode utilizar-se das habilidades e dos conhecimentos existentes em sua turma para potencializar as suas próprias habilidades e conhecimentos.

Todavia, por que a utilização dessa estratégia parece ser inviável para a maioria dos professores em atividade? Uma possível resposta pode estar justamente no processo de formação desse professor. Sem entrar no mérito da qualidade ou do conteúdo expresso nas matrizes curriculares dos cursos de licenciatura, o que parece que é o discurso tradicional a respeito do papel de autoridade do professor, defendido por Durkheim (2008), ainda permanece, de forma implícita ou explícita, no processo formativo desses docentes.

Nesse processo, também percebido por Furlani (2012), é recorrente reconhecer a ausência de diálogo e a constituição de uma relação unidirecional, na qual aquele que quer respeito (o professor), não se vê obrigado a também respeitar o outro (o aluno). Quando esse quadro se instala, é possível que o professor incorra no erro de exercer a sua autoridade a partir de formas de tirania ou de autoritarismo. A partir desse momento, o uso da tecnologia, por exemplo, não mais se configuraria como um simples procedimento de organização existente na sala de aula, mas, 
sim, como um ponto de resistência e conflito constituído a partir das tentativas de manutenção das relações de poder que emergem no ato educativo.

Assim, o professor teria que superar a aplicação de procedimentos de ensino homogeneizantes e que não reconhecem o aluno, também, como um protagonista do processo. Essa perspectiva de raciocínio está bem alinhada à reflexão levantada por Reis e Lunardi-Mendes (2018), ao pesquisarem sobre o uso de tecnologias digitais por jovens professores, bem como de Bonilla e Pretto (2015) e Zabala (2010), ao afirmarem que as novas necessidades educacionais do século XXI não podem acolher mais a utilização de uma metodologia rígida, acabada e intransigente, e que não levam em consideração as experiências do aluno e a sua necessidade de compreender a realidade. Para tanto, cabe ao professor reconhecer as necessidades dos alunos e construir mecanismos que possam atendê-las durante sua prática cotidiana (TURRA-DIAS; FLORES-LUEG, 2018).

O resultado identificado também parece compactuar com a visão de Alarcão (2007), de que o professor possui papel preponderante no desenvolvimento de uma relação de autoaprendizagem em sala de aula, o que exigirá do professor a percepção de que soluções generalistas e rotineiras não são mais efetivas frente à nova geração de alunos. Essa ideia reforça, ainda mais, que, somente por meio da cooperação, dos olhares multidimensionais e de uma investigação minuciosa é que o ato educativo alcançará o seu objetivo de formação. Essa reflexão parece levantar um outro ponto muito importante a respeito desse tema: a competência de identificar as melhores estratégias de aula, tendo como ponto de partida a necessidade dos alunos, a cooperação e a construção conjunta dos procedimentos cotidianos parece ser significativamente mais relevante do que o domínio tecnológico, que é cobrado usualmente dos professores pelas instituições de ensino.

\section{Considerações finais}

As dinâmicas sociais identificadas, a partir da análise do DSC e da observação assistemática, caminham para uma posição de contrariedade ao que se encontra defendida por boa parte da literatura que trabalha o conceito do uso da tecnologia na Educação e na formação do professor. Muitas vezes vista como a panaceia para os problemas educacionais, as TICs parecem ter um caminho ainda longo de amadurecimento, antes de ter impactos significativos na Educação, pelo menos no que tange às promessas já feitas para esse contexto.

Enquanto resultado da pesquisa, as TICs se compõem como uma das variáveis importantes no processo educacional e, como tal, também pode reforçar ou 
desconstruir a autoridade docente, não pela ação direta, como geralmente é defendido, mas pela forma com que ela é trabalhada pelo docente. Ou seja, não parece ser o domínio das TICs pelo professor que reforça, ou não, a sua autoridade, mas como ele, tendo ou não esse domínio, utiliza-se das competências inerentes aos seus alunos para potencializar os seus próprios recursos didáticos e permitir uma construção metodológica conjunta com a sua turma. Essa construção possibilitaria que o aluno enxergasse sentido e significado nas ações do professor e, por meio de um objetivo comum e compartilhado, as competências do docente reforçariam cada vez mais o seu papel como "responsável pelo mundo", como Arendt (2011) distingue.

Percebe-se, também, a existência de um discurso que potencializa as pressões quanto ao uso das TICs nas instituições de ensino e na formação do professor. Parece ser "terreno comum" defender que, somente por meio das TICs, a Educação poderia sair do que seria "a sua maior crise" e entrar em uma nova era de excelência. É importante estudar a fonte desses discursos e os interesses que estão por trás dessas pressões, principalmente quando verifica-se que os investimentos financeiros, materiais e de recursos humanos, que são destinados a essa temática, compõem um cenário econômico, que poderia ser manipulado em benefício de setores que não seriam diretamente ligados à Educação.

É importante frisar que o contexto de perda da autoridade docente é reconhecido pelos professores participantes da pesquisa. Contudo, a perda dessa autoridade não é composta por um único ou novo fenômeno, mas por um conjunto de fatores diversos, que acompanham o que foi percebido como uma crise educacional decorrente das novas mudanças sociais.

A pesquisa também aponta que a afirmação recorrente de que o professor é incapaz de acompanhar o domínio tecnológico da mesma maneira de que o seu aluno pode estar equivocada. O professor também vivencia os desafios apontados no conceito de "Sociedade da Informação", que é apresentado por Castells (2009), tendo acesso aos mesmos recursos e deles servindo-se para ser incluído na tessitura social. Ainda que o seu aprendizado seja mais lento, ele não se constitui como um ser a parte das mudanças da sociedade e não sofre o mesmo tipo de influência que ela projeta.

Por fim, entende-se que as TICs se constituem enquanto mais uma das diversas variáveis que podem reforçar ou desconstruir a autoridade docente, mas ela não é vista como a mais crítica ou mais importante. A sua influência está muito mais relacionada à percepção de seu uso pelo professor do que, necessariamente, 
pelo seu domínio. O professor que possui as competências necessárias para manter um equilíbrio entre as necessidades de aprendizagem dos seus alunos e as ferramentas para suprir essas necessidades, poderá utilizar-se da tecnologia para reforçar a sua autoridade, mesmo quando não possuir um domínio maior sobre a sua técnica. Por outro lado, o professor, mesmo possuindo um vasto domínio das TICs, caso não consiga estabelecer relações de sentido e significado com o seu aluno, terá a sua autoridade e legitimidade destituídas pela turma. 


\title{
The teaching authority and the information society: the role of information technology in teaching
}

\begin{abstract}
This paper aims to identify how the technologies and the teaching practice in the "Information Society" reinforce or challenge the teacher's perception of his/her authority. Hannah Arendt's works are the main theoretical pillar. This qualitative research project used the analysis of collective subject discourse. Results identified that students easily interacted with technology, since this use does not exceed the communication and leisure contexts. Furthermore, students' access to the new informational bases in fact can generate a feeling of loss of authority on the part of the unprepared teacher. At last, the mastery of technology by the teacher does not establish his/her authority, but rather the relation of meaning constructed during the educational relationship.
\end{abstract}

Keywords: Teacher Authority. Education crisis. Technology. Information. Uncertainty.

\section{La autoridad docente y la sociedad de la información: el papel de las tecnologías de información en la docencia}

\section{Resumen}

Este trabajo tuvo como objetivo identificar las formas por las cuales las tecnologías y la práctica docente en relación con la "sociedad de información" refuerzan o afectan negativamente la percepción de los profesores y su autoridad por los estudiantes. La reflexión relativa al concepto de autoridad por Hannah Arendt basó teóricamente y conceptualmente esta investigación. Esta investigación cualitativa utilizó la técnica del discurso del sujeto colectivo. Los resultados revelan que los estudiantes tienen facilidad de interactuar con las tecnologías, pero solamente en los contextos de comunicación y diversión; que el acceso de los discentes a las nuevas bases informacionales puede generar un sentimiento de pérdida de autoridad por el profesor menos preparado y que no es el dominio de la tecnología por el docente que fundamenta su autoridad, pero la constitución del significado construido durante la relación educativa.

Palabras clave: Autoridad docente. Crisis educativa. Tecnología. Información. Incertidumbre. 


\section{Referências}

ALARCÃO, I. Escola reflexiva e nova racionalidade. Porto Alegre: Artmed, 2007.

ANASTASIOU, L. G. C. A docência no Ensino Superior: desafios e possibilidades. Forgrad em Revista, Vitória, n. 1, p. 5-8, maio 2006.

ARENDT, H. A crise na Educação. In: ARENDT, H. Entre o passado e o futuro. São Paulo: Perspectiva, 2011.

BAUERLEIN, M. The dumbest generation: how the digital age stupefies young Americans and Jeopardizes our future (or, don't trust anyone under 30). Los Angeles: TarcherPerigee, 2008.

BAUMAN, Z. 44 Cartas do mundo líquido moderno. Rio de Janeiro: Jorge Zahar, 2011.

BLÖMEKE, S.; BUCHHOLTZ, C. Veränderung von Lehrerhandeln beim Einsatz neuer Medien. Design für die theoriegeleitete Entwicklung, Durchführung und Evaluation einer Intervention. MedienPädagogik: Zeitschrift für Theorie und Praxis der Medienbildung, [s. l.], p. 91-106, Set. 2017. https://doi.org/10.21240/mpaed/retro/2017.09.06.X

BONILLA, M. H. S.; PRETTO, N. L. Política educativa e cultura digital: entre práticas escolares e práticas sociais. Perspectiva, Florianópolis, v. 33, n. 2, p. 499-521, 2015. https://doi.org/10.5007/2175-795X.2015v33n2p499

CASTELLS, M. A sociedade em rede. São Paulo: Paz e Terra, 2009.

CECCHETTINI, E. E. B. Introdução. In: VERAS, M. Inovação e métodos de ensino para nativos digitais. São Paulo: Atlas, 2011.

CHRISTENSEN, C. M.; HORN, M.; JOHNSON, C. W. Inovação na Sala de Aula: Como a inovação disruptiva muda a forma de aprender. Porto Alegre: Bookman, 2012.

DURKHEIM, E. Educação e sociologia. São Paulo: Hedra, 2008.

ENGUITA, M. F. La educación en la encrucijada. Madrid, Fundación Santillana, 2016.

FRANKY, A. P.; CHIAPPE, A. Famílias que educam em casa com TIC: um estudo qualitativo de múltiplos casos. Ensaio: Avaliação e Políticas Públicas 
em Educação, Rio de Janeiro, v. 26, n. 101, p. 1324-1346, out./dez. 2018. https://doi.org/10.1590/s0104-40362018002601507

FURLANI, L. M. T. Autoridade do professor: meta, mito ou nada disso? 9. ed. São Paulo: Cortez, 2012.

HALLOWELL, E. Sem tempo pra nada: vencendo a epidemia da falta de tempo. Rio de Janeiro: Nova Fronteira, 2007.

HOWE, N.; STRAUSS, W. Millennials rising: the next great generation. 5. ed. [s. l.]: Vintage, 2009.

JUKES, I.; DOSAJ, A. Understanding digital kids (DKs): teaching and learning in the new digital landscape. [s. l.]: The InfoSavvy Group, 2004. Disponível em: http://jayneturner.pbworks.com/w/file/fetch/28960161/ growingupdigit.pdf. Acesso em: 24 dez. 2018.

LANDWEER, H.; NEWMARK, C. Verdeckte Autorität.: Moderne Gefühlsdynamiken. Deutsche Zeitschrift für Philosophie, [s. l.], v. 65, n. 3, p. 504-19, 2017.

LEFEVRE, F.; LEFEVRE, A. M. C. Depoimentos e discursos: uma proposta de análise em pesquisa social. Brasília, DF: Líber Livro, 2005.

LIMA, V. M. R.; GILLO, M. C. Por que o professor faz o que faz na sala de aula? O fazer pedagógico e as concepções de conhecimento. In: FREITAS, A. L. S.; GESSINGER, R. M. (org.). A gestão da aula universitária na PUCRS. Porto Alegre, EDIPUCRS, 2008. p. 19-32.

OLIVEIRA, S. Geração Y: era das conexões, tempo de relacionamentos. São Paulo, Clube de Autores, 2009.

POSTIC, M. A relação pedagógica. Coimbra: Coimbra Editora, 1990.

PRENSKY, M. The emerging online life of the digital native: what they do differently because of technology, and how they do it. 2004. Disponível em: http://www.marcprensky.com/writing/Prensky-The_Emerging_Online_Life_ of_the_Digital_Native-03.pdf. Acesso em: 23 jan. 2019.

REIS, V.; LUNARDI-MENDES, G. M. De iniciantes a vanguardistas: o uso de tecnologias digitais por jovens professores. Holos, [s. l.], v. 1, p. 297-316, fev. 2018. 
SCHLEMMER, E. O trabalho do professor e as novas tecnologias. Textual, Porto Alegre, v. 1, n. 8, p. 33-42, 2006.

SOSA, O. G.; MANZUOLI, C. H. Modelos para a integração pedagógica de tecnologias de informação e comunicação: uma revisão da literatura. Ensaio: Avaliação e Políticas Públicas em Educação, Rio de Janeiro, v. 27, n. 102, p. 129-156, jan./mar. 2019. https://doi.org/10.1590/s0104-40362018002701720

SOUSA, C. A. L. Professor, quero ser oprimida! Situação-limite e atos-limites no habitus professoral. Linhas Críticas, Brasília, DF, v. 18, n. 37, p. 551-568. set./dez. 2012. https://doi.org/10.26512/lc.v18i37.4010

SOUSA, C. A. M.; LIMA, D. M. S.; FONTE-BOA, F. Jovens universitários de licenciatura e a educação a distância $(\mathrm{EaD})$ em seus cursos presenciais. In: SOUSA, C. A. M. S. (org.). Juventudes e tecnologias: sociabilidades e aprendizagens. Brasília, DF: Liber Livro: Unesco, 2015. p. 155-172.

TAKAHASHI, T. (org.). Sociedade da informação no Brasil. Brasília, DF: Ministério da Ciência e Tecnologia, 2000.

TAPSCOTT, D. Grown Up digital: how the net generation is changing your world. New York: McGraw-Hill, 2008.

TURRA-DIAZ, O.; FLORES-LUEG, C. La formación práctica desde las voces del estudiantado de pedagogía. Ensaio: Avaliação e Políticas Públicas em Educação, Rio de Janeiro, v. 27, n. 103, p. 385-405, abr.jun. 2018. http://dx.doi.org/10.1590/s0104-40362018002601517

ZABALA, A. A prática educativa: como ensinar. Porto Alegre: Artmed, 2010. 


\section{Informações dos autores}

Leonardo Humberto Soares: Doutor em Educação pela Universidade Católica de Brasília. Professor do Centro Universitário de Brasília e Assessor Pleno da Área de Gestão da União Marista do Brasil. Contato: leonardo.humberto.soares@gmail.com

iD http://orcid.org/0000-0003-0127-3273

Carlos Ângelo de Meneses Sousa: Doutor em Sociologia pela Universidade de Brasília. Professor Permanente do Programa de Mestrado e Doutorado em Educação da Universidade Católica de Brasília. Pesquisador da Cátedra Unesco de Juventude, Educação e Sociedade da mesma universidade. Contato: carlosangeloms@gmail.com

iD http://orcid.org/0000-0001-9228-3420

Ricardo Spindola Mariz: Doutor em Sociologia pela Universidade de Brasília. Coordenador da Área de Missão e Gestão da União Marista do Brasil. Contato: marizricardo@gmail.com

iD http://orcid.org/0000-0002-3398-059X

Jaci Maria Ferraz de Menezes: Doutora em Educação pela Universidade Católica de Córdoba, Argentina. Professora do Programa de Pós-Graduação em Educação e Contemporaneidade da Universidade do Estado da Bahia. Contato: jacimnz@hotmail.com

iD https://orcid.org/0000-0001-9889-4257 